\title{
O fantasma de Pepper e sua contribuição para o ensino de óptica geométrica
}

\author{
Denise Vieira da Rocha Abreu ${ }^{1}$, Adellane Araujo Sousa² \\ 1, 2 Universidade Federal da Grande Dourados (UFGD)
}

Palavras-Chave: Ensino de Física, Fantasma de Pepper, Refração, Reflexão Interna Total.

\section{Introdução}

O Fantasma de Pepper é uma das ilusões de óptica mais fascinante e reproduzida no mundo em mais de cem anos, formando curiosas imagens virtuais que parecem se fundir com objetos reais, demonstrando que por trás da aparente mágica há conceitos físicos que podem ajudar a construir "pontes" para os alunos adentrarem no mundo das ciências ensinadas no ensino médio.

Atualmente existem muitas dificuldades para ensinar física, notadamente conteúdos de Óptica como a Geométrica. Dentre estas dificuldades, de acordo com Bertelli (2013), podemos destacar: alunos desmotivados, escolas sem laboratórios, professores com práticas pedagógicas limitadas ao quadro e giz, conteúdos sendo trabalhados de maneira isolada sem relacionar ao cotidiano do aluno, contribuindo para o fracasso da aprendizagem da disciplina.

A fim de tentar contornar estas dificuldades, construímos alguns dispositivos baseados nos princípios da óptica envolvendo "O Fantasma de Pepper", buscando apresentar uma proposta envolvendo a "mágica" dessas ilusões de óptica como ferramenta no processo ensinoaprendizagem, conforme visto na figura 1. Segundo Parisoto e Hilger (2016), a aprendizagem é facilitada quando o aluno está interessado e as ilusões de óptica despertam a curiosidade em aprender como elas ocorrem, contribuindo assim para o ensino de Física.

Figura 1- Ilustração do efeito "Fantasma de Pepper".

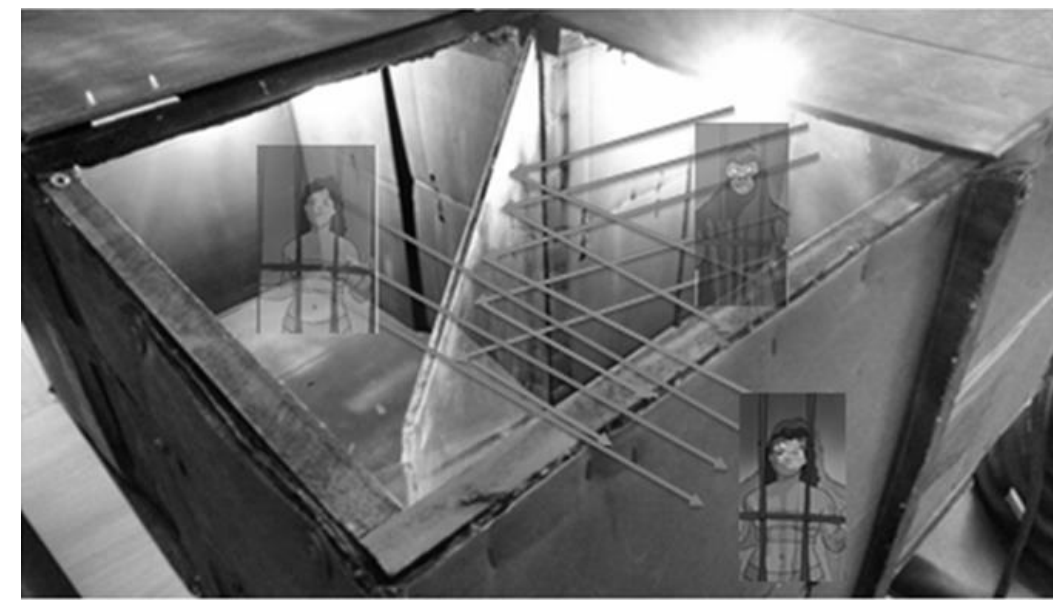

Fonte: Denise V. da Rocha Abreu. UFMT. Campus Barra do Garças.MT. Out. 2018.

\section{Metodologia e Material}

Nossa metodologia consiste em contribuir para o ensino de Física de forma criativa. De acordo com Medeiros (2006), o mistério e a diversão são ferramentas que auxiliam o professor de Física na criação, análise, discussão e decodificação científica dos conceitos envolvidos nas ilusões de óptica.

Dessa forma, desenvolvemos uma proposta alternativa para ensinar os conceitos de óptica geométrica envolvendo os fenômenos de reflexão, refração e reflexão interna total.

Trata-se de uma proposta que foi elaborada e desenvolvida com alunos do $2^{\circ}$ ano $B$ do Ensino Médio do CEPMG- João Augusto Perillo, Cidade de Goiás-GO, em outubro de 2018, com 34 alunos matriculados.

Utilizou-se uma sequência didática com questionário prévio sobre a familiaridade dos alunos com a óptica, construção de um conjunto de dispositivos que realizam ilusões de óptica para realizar




experimentos em sala de aula, questionário sobre o experimento aplicado, bem como a opinião dos alunos quanto à metodologia adotada e análise da evolução conceitual alcançada através de uma avaliação final.

Nosso tema gerador foi o Fantasma de Pepper, apresentando sua evolução ao longo do tempo, sua finalidade de criação para o entretenimento e o seu uso como recurso pedagógico. Construímos um aparato simulando o dispositivo de Dircks, o dispositivo de John Pepper e a Pirâmide Holográfica (falso holograma).

\section{Resultados e Discussão}

Nosso intuito foi levar o aluno a compreensão dos temas abordados, mostrando que a Física não se resume somente a fórmulas e problemas mais abstratos.

Foi possível perceber melhora na aprendizagem dos conceitos envolvidos, mostrando sua aplicabilidade e importância na vida cotidiana.

Podemos sugerir que a experimentação aliada com atividades adequadas e dirigidas exerce grande impacto na participação e interesse do aluno, melhorando a interação com o professor e demais colegas, e consequentemente, propiciando aprendizagem dos conteúdos trabalhados.

\section{Conclusões}

Os experimentos e atividades realizadas com os dispositivos despertaram o interesse e a curiosidade nos alunos para compreenderem os conceitos físicos envolvidos, colaborando no processo de aprendizagem. Consideramos que foi uma experiência bem-sucedida, pois os alunos demonstraram envolvimento na resolução das atividades e motivação para aprender.

\section{Agradecimentos}

O presente trabalho foi realizado com apoio da Coordenação de Aperfeiçoamento de Pessoal de Nível Superior - Brasil (CAPES) - Código de Financiamento 001.

\section{Referências}

MEDEIROS, A. A história e a física do fantasma de Popper. Caderno Brasileiro de Ensino de Física, v.23, n.3, p. 329-344, dez. 2006. Disponível em:

<https://periodicos.ufsc.br/index.php/fisica/article/view/5811>. Acesso em: 16 ago. 2017.

PARISOTO, M. F.; HILGER, T. R. Investigação da aprendizagem de conceitos de óptica utilizando ilusões para turmas de pré-vestibular. Revista Brasileira de Ensino de Ciência e Tecnologia, Ponta Grossa, v. 9, p. 62-98, jan/abr. 2016. Disponível em:

<https://periodicos.utfpr.edu.br/rbect/article/view/2109> Acesso em: 06 jun. 2017.

BERTELLI, L. G. Quanto mais estudo, melhor.

Disponível em: <http://www.administradores.com.br/noticias/carreira/quanto-mais-estudomelhor/76692/> Acesso em: 14 out. 2017. 